\title{
IMPROVEMENT THROUGH EMOTIONAL INTELLIGENCE GROUP COUNSELING SERVICES WITH STUDENTS PSYCHOANALYTIC APPROACH SMP STATE 11 PADANGSIDIMPUAN
}

\author{
Khairul Amri, M.Pd \\ Universitas Muhammadiyah Tapanuli Selatan \\ Email: khairul.amri@um-tapsel.ac.id
}

abstrak

The study was based on the problems that still lack emotional intelligence of students. The study goal was to describe the emotional intelligence of students before and after the group gave guidance services, with the psychoanalytic approach. The method used in this research is True experimental design with shapes pretest-posttest control group design. With a sample of experimental class is class VII-1 by 10 students and the control class is class VII-2 as many as 10 students so as the total sample of 20 students. Data collection techniques in this research using questionnaires, distributing questionnaires aim is to obtain the specific information requested. Data were analyzed with the help of Excel or SPSS (Statistical Product and Service Solution) version 20. From the results of the implementation is done, a significant increase is mainly posttest experiment. The findings in the experimental group and the control group there were significant increases between posttest results and posttest control experiment. The average child's emotional intelligence variable Pre-Test and Post-Test class in looking for the experimental and control average. In the experimental group pre-test value is obtained at 91.7 and the control class values obtained pre-test of 120.5. While the results of the post-test experimental class obtained a value of 87.6 and a post-test values at control class is 107.0 is seen a very significant difference. The conclusion of this study the results of the processing of the data, indicate that the implementation of guidance services group with psychoanalytic approach can improve the emotional intelligence of students of SMPN 11 Padangsidimpuan.

Keywords: Increasing Emotional Intelligence, Guidance Services Group With Psychoanalytic Approach

\section{PENDAHULUAN}

Setiap anak pada hakekatnya juga mempunyai sebuah kemampuan yang memang sudah terdapat di dalam dirinya semenjak dilahirkan, kemampuan ini dinamakan potensi. Potensi dapat dikembangkan dengan baik apabila didukung oleh faktor dari dalam diri manusia sendiri dan faktor lingkungan.

Seandainya potensi yang ada pada seseorang tidak mampu dikembangkan secara efisien, tidak akan menjamin kehidupannya akan berhasil. Pengembangan potensi anak dapat dilakukan oleh orang tua, guru dan dijalani oleh anak. Sebagaimana yang dijelaskan bahwa
Untuk itu kecerdasan emosional atau Emosional Question adalah salah satu kecerdasan yang harus diasah dan di kembangkan sejak dini, supaya anak-anak untuk menghadapi kehidupan di masa yang akan datang, akan lebih baik dan bijaksana menyikapi kehidupannya.

Salah satu komponen pendidikan yang memiliki peranan dalam mengembangkan kecerdasan emosional adalah guru bimbingan dan konseling. Guru bimbingan dan konseling yang hadir di sekolah-sekolah adalah memiliki peranan dan tanggung jawab terhadap perkembangan 
peserta didik terutama hal-hal yang berkaitan dengan kecerdasan di luar akademik.

Guru bimbingan dan konseling atau sekarang disebut dengan guru pembimbing memiliki berbagai alternatif layanan yang dapat digunakan sebagai media pengembangan dan pengentasan masalah siswa, begitu juga halnya dengan masalah kecerdasan emosional. Salah satu layanan yang dapat digunakan adalah layanan bimbingan kelompok.

Pelayanan Bimbingan dan Konseling di sekolah yang salah satunya berisikan tentang layanan bimbingan kelompok bertujuan untuk membantu siswa agar dapat menjalani kehidupannya, baik untuk kehidupan sehari-hari sekarang maupun untuk perencanaan hidupnya kedepan. Layanan Informasi ini dapat diperoleh dari berbagai sumber terutama sumber yang dari anggota kelompok, dimana anggota kelompok memperoleh informasi dari media lisan melalui perorangan, media tertulis dan grafis, melalui sumber formal dan informal, sampai dengan media elektronik melalui sumber teknologi tinggi (Prayitno,2004;3).

Pendekatan psikoanalitik menekan pada fungsi Id, Ego dan Superego manusia. Pendekatan Psikonalitik lebih mengedepankan bagiamana individu dapat memfungsikan ketiga unsur tersebut( Gerrald, 2004;80).

Dengan demikian bimbingan kelompok yang dikombinasikan dengan pendekatan psikoanalitik akan memberikan suasana yang berbeda mulai dari dinamika kelompok yang di ciptakan oleh pemimpin kelompok, sampai kepada pendekatan yang psikonalitik dan kemampuan memfungsikan id sebagai sumber keinginan dan ego sebagai bentuk tindakan dan superego sebagai terminal ke arah mana tindakan yang harus dilakukan oleh seorang individu, dengan demikian bimbingan kelompok dengan pendekatan Psikoanalitik akan mempertegas dalam penyelenggaraannya memiliki variasi dan pendekatan khusus agar klien atau anggota kelompok dapat membentuk secara langsung kecerdasan emosional.
Berdasarkan latar belakang di atas dapat di identifikasi permasalahan antara lain:

a. Kurangnya kecerdasan emosional siswa

b. Merasa minder dengan temannya

c. Siswa tidak masuk ruangan karena tidak menyukai gurunya

d. Kecerdasan Emosional tidak dibina secara intensif

e. Motivasi belajar menurun akibat tidak mampu mengendalikan suasana hati

\section{METODE PENELITIAN}

Dalam penelitian ini penulis menggunakan metode eksprimen. Sebagaimana dikatakan Suharsimi Arikunto (2009:207) Metode eksperimen merupakan penelitian yang dimaksudkan untuk mengetahui ada tidaknya akibat dari sesuatu yang dikenakan pada subjek selidik. Dengan kata lain penelitian eksperimen mencoba ada tidaknya hubungan sebab akibat. Selanjutnya Sugiyono (2009:107) menyatakan penelitian eksprimen adalah sebagai metode penelitian yang digunakan untuk mencari pengaruh perlakuan tertentu terhadap yang lain dalam kondisi yang terkendalikan.

Dari pendapat di atas dapat disimpulkan bahwa pretest posttest control group dalam model ini terdapat kelompok eksperimen dan kelompok kontrol.

Dalam penelitian ini dilakukan tes sebanyak 2 kali yaitu sebelum eksperimen dan sesudah. Desain ini di gambarkan melalui pendapat sugiyono (2009: 112 ) dengan rumus pretest posttest control group design adalah dalam desain ini terdapat dua kelompok yang pilih kemudian di beri pretest untuk mengetahui keadaan awal adakah perbedaan antara kelompok eksprimen dan kelompok kontrol:

\section{Populasi}

Suharsimi Arikunto (2009: 134) Populasi adalah keseluruhan subjek penelitian. Apabila seorang meneliti semua elemen yang ada dalam wilayah penelitian, maka penelitiannya merupakan penelitian populasi. 
Berdasarkan pendapat diatas populasi adalah keseluruhan objek yang diteliti. Jadi yang menjadi populasi dalam penelitian ini adalah seluruh siswa kelasVII SMP Negeri 11 Padangsidimpuan yang berjumlah 86 siswa. Untuk lebih jelas dapat dilihat pada tabel berikut:

Tabel. 1

Distribusi Siswa SMP Negeri 11 Padangsidimpuan Sebagai Populasi Penelitian

\begin{tabular}{|c|c|c|}
\hline Kelas & $\begin{array}{c}\text { Populasi } \\
\text { L/P }\end{array}$ & Keterangan \\
\hline $\mathrm{VII}^{1}$ & 29 & \\
\hline $\mathrm{VII}^{2}$ & 28 & \\
\hline $\mathrm{VII}^{3}$ & 29 & \\
\hline Jumlah & \multicolumn{2}{|c|}{86} \\
\hline
\end{tabular}

\section{Sampel}

Menurut Sugiyono

menyatakan Sampel adalah bagian dari jumlah dan karakteristik yang dimiliki oleh populasi tersebut.

Berdasarkan penjelasan para ahli diatas, penulis menyimpulkan bahwa sampel adalah sebagian dari populasi yang diteliti. Teknik pengambilan sampel yang digunakan adalah Sampling purposive yaitu teknik penentuan sampel dengan pertimbangan tertentu.

Dalam penelitian ini, maka sampel yang diambil adalah sebagian siswa kelas VII SMP Negeri 11 Padangsidimpuan yang berjumlah 20 siswa. Untuk lebih jelas dapat dilihat pada tabel berikut:

Tabel . 2

Distribusi Siswa SMP Negeri 11 Padangsidimpuan

\section{Teknik Pengumpulan Data}

Dalam penelitian ini digunakan beberapa metode pengumpulan data sesuai dengan data yang ingin dikumpulkan dan variabel yang akan diteliti, maka penelitian ini menggunakan angket sebagai instrumen utamanya untuk teknik pengambilan data di lapangan.

Selama pelaksanaan bimbingan kelompok, peneliti juga menggunakan metode angket.

Menurut Sugiyono (2009:199) “Angket adalah teknik pengumpulan data yang dilakukan dengan cara memberi seperangkat pertanyaan atau pernyataan tertulis kepada responden untuk di jawabnya.

. Tujuan penyebaran angket ialah untuk mendapatkan informasi tertentu yang diminta. Angket digunakan untuk menjaring tentang kondisi kecerdasan emosional siswa kelas VII SMP Negeri 11 Padangsidimpuan. Alasan digunakannya metode angket adalah subyek merupakan orang yang paling tahu tentang dirinya sendiri. Dapat digunakan secara serentak, dan terhindar dari pengaruh orang lain dan objek di luar individu, sehingga data yang diperoleh dapat di percaya.

\section{Teknik Analisis Data}

Setelah data dikumpulkan, penulis menggunakan analisi data yaitu analisis dan statistik. Sebagai tambahan untuk mengetahui criteria skor penilaian.

Tabel. 3

Skor Penilaian

\begin{tabular}{|c|c|c|}
\hline No & Interval & Interpretasi \\
\hline 1 & $80-100$ & Sangat Baik \\
\hline 2 & $70-79$ & Baik \\
\hline 3 & $60-69$ & Cukup \\
\hline 4 & $50-59$ & Kurang \\
\hline 5 & $0-49$ & Gagal \\
\hline
\end{tabular}

\begin{tabular}{|c|c|c|c|c|}
\hline Kelas & $\mathbf{L}$ & $\mathbf{P}$ & Jumlah & Keterangan \\
\hline $\mathrm{VII}_{1}$ & 4 & 6 & 10 & Eksperimen \\
\hline $\mathrm{VII}_{2}$ & 3 & 7 & 10 & Kontrol \\
\hline \multicolumn{3}{|c|}{ Jumlah } & 20 & \\
\hline
\end{tabular}

Data dalam penelitian ini diperoleh dari objek penelitian untuk mengungkapkan sejauh mana peningkatan kecerdasan emosional siswa. Dalam penelitian ini setelah data dari nilai tes 
awal (pretest) dari kelas eksperimen dan control langkah-langkah sebagai berikut: Pertemuan telah terkumpul, maka proses pengelolaan data tahap pertama diberikan pretest dengan dengan menggunakan program computer dengan melihat kecerdasan emosional yang dimiliki bantuan Exel atau program SPSS (Statistical siswa. Pertemuan tahap ke dua diberikan Product and Service Solution) versi 20. Dengan layanan konvensional berupa layanan tahap-tahap:

a. Editing

Proses pencetakan atau memeriksa data yang telah berhasil dikumpulkan dari lapangan, karena ada kemungkinan data yang masuk tidak memenuhi syarat atau tidak dibutuhkan.

b. Codeting

Kegiatan pemberian kode tertentu pada tiap-tiap data yang termasuk pada kategori yang sama

c. Tabulasi informasi, selanjutnya kordinator BK memberikan posttest.

Dari hasil perbandingan antara kelas eksperimen dengan kelas kontrol, menunjukkan bahwa hasil penelitian lebih tinggi pada kelas eksperimen daripada hasil penelitian pada kelas kontrol. Dengan demikian peneliti dapat menyimpulkan bahwa kegiatan layanan bimbingan kelompok yang dilakukan oleh peneliti lebih besar berpengaruh untuk meningkatkan Proses penempatan kedalam bentuk tabel yang telah diberikan kode sesuai dengan kebutuhan analisis.

\section{HASIL}

Hasil dari penelitian dan pembahasan mengenai penelitian dengan judul "Peningkatan Kecerdasan Emosional melalui Layanan Bimbingan Kelompok dengan Pendekatan Psikoanalitik Siswa SMP Negeri 11 Padangsidimpuan" yang telah dilaksanakan.

Pelaksanaan penelitian eksperimen yang dilakukan oleh peneliti dengan langkah-langkah sebagai berikut: Pertemuan tahap pertama seleksi sampel penelitian yang akan diberikan pretest dengan melihat kecerdasan emosional yang dimiliki siswa dan selanjutnya disebut sebagai anggota kelompok. Pertemuan tahap ke dua dan kecerdasan emosional siswa.

Dari skor yang diperoleh masing-masing indikator terlihat adanya peningkatan motivasi belajar sesudah diberikannya perlakuan layanan bimbingan kelompok pada kelompok eksperimen.

Hasil dari pengujian hipotesis diperoleh bahwa peningkatan kemampuan motivasi belajar siswa dapat ditingkatkan dengan menggunakan layanan bimbingan kelompok. Sehingga terbukti bahwa layanan bimbingan kelompok efektif untuk meningkatkan motivasi belajar, selain dapat meningkatkan peningkatan motivasi belajar juga dapat meningkatkan hasil belajar siswa.

Peningkatan hasil prestest dan posttest disebabkan karena perlakuan layanan bimbingan kelompok yang diberikan oleh konselor. Melalui layanan bimbingan kelompok, siswa merasakan bebasnya menyampaikan pendapat, dapat mengembangkan perasaan, pikiran, persepsi, wawasan dan sikap yang menunjang tingkah laku ketiga dilakukan kegiatan layanan bimbingan untuk mengendalikan diri, tenggang rasa dan kelompok dan kemudian peneliti sumbang saran kepada sesama anggota memberikan treatment 2 kali, dengan kelompok. Siswa dalam kegiatan layanan ini penentuan waktu disepakati oleh anggota. banyak memperoleh hal baru yang sesuai dengan Setelah Pemberian treatmen sebanyak dua pendapat Prayitno, (2012;54). Yaitu tenaga kali selanjutnya pertemuan tahap keempat bimbingan memanfaatkan proses kelompok diberikan posttest.

Pelaksanaan penelitian kontrol yang dilakukan oleh koordinator BK dengan (group procces), yaitu interaksi dan komunikasi yang berlangsung antara anggota peserta kelompok yang bekerjasama untuk memenuhi 
suatu kebutuhan yang dihayati bresama melalui penukaran dalam diskusi, atau untuk merencanakan suati aksi yang akan dilaksanakan bersama. Kemudian dapat diketahui melalui informasi yang diterima siswa melaui kegiatan bimbingan kelompok yang diterima siswa melalui kegiatan bimbingan kelompok menjadi wawasan bagi meraka agar dapat menyusun rencana yang tepat khususnya dalam motivasi belajar.

Berdasarkan kutipan di atas disimpulkan bahwa bimbingan kelompok merupakan media bagi siswa untuk mengembangkan diri dan memperoleh media bagi siswa untuk mengembangkan diri dan memperoleh informasi, yang kemudian informasi tersebut akan dipergunakan untuk menyusun rencana dan membuat keputusan dalam kehidupannya serta mampu secara pribadi berfikir lebih terarah khususnya untuk dapat meningkatkan motivasi belajar siswa.

Berdasarkan hal tersebut maka peningkatan motivasi belajar dapat ditingkatkan dengan menggunakan layanan bimbingan kelompok, hal ini karena siswa dapat membangun hal baru yang lebih efektif dan berfikir yang mempengaruhi perilaku, watak dan sifat di dalam kehidupan pribadi dan lingkungannya.

Tabel. 4

Interval Perbandingan Hasil Angket Kecerdasan Emosional

Kelas Eksperimen dan Kelas kontrol

\begin{tabular}{|c|c|c|c|c|c|c|c|c|c|c|c|c|}
\hline \multirow{2}{*}{$\begin{array}{c}\text { No } \\
\text {. }\end{array}$} & \multirow{2}{*}{$\begin{array}{c}\text { Nilai } \\
\text { Interva } \\
\text { I }\end{array}$} & \multicolumn{2}{|c|}{$\begin{array}{c}\text { Eksperime } \\
\text { n }\end{array}$} & \multicolumn{2}{|c|}{ Kontrol } & \multirow{2}{*}{$\begin{array}{c}\text { Katego } \\
\text { ri }\end{array}$} & \multicolumn{6}{|c|}{$\begin{array}{ll} & \text { Tabel. } 5 \\
\end{array}$} \\
\hline & & Pre & Post & Pre & Post & & \multirow{2}{*}{\multicolumn{6}{|c|}{$\begin{array}{c}\text { Perbandingan Hasil Per Sampel Pre-Test dan } \\
\text { Post-Test } \text { Kelas Eksperimen dan Kelas } \\
\text { Kontrol }\end{array}$}} \\
\hline 1. & $\begin{array}{c}131- \\
150\end{array}$ & & & & & $\begin{array}{l}\text { Sangat } \\
\text { Baik }\end{array}$ & & & & & & \\
\hline \multirow{2}{*}{2.} & \multirow{2}{*}{$\begin{array}{l}111- \\
130\end{array}$} & & \multirow{2}{*}{$\begin{array}{c}120, \\
5\end{array}$} & & & \multirow{2}{*}{ Baik } & \multirow{2}{*}{$\begin{array}{c}\text { Kode } \\
\text { Sampel }\end{array}$} & \multirow{2}{*}{ Indikator } & \multicolumn{2}{|c|}{ Eksperimen } & \multicolumn{2}{|c|}{ Kontrol } \\
\hline & & & & & & & & & Pre- & Post- & Pre- & Post- \\
\hline \multirow[t]{2}{*}{3.} & \multirow[t]{2}{*}{$91-110$} & \multirow{2}{*}{$\begin{array}{c}91, \\
7\end{array}$} & & & \multirow{2}{*}{$\begin{array}{c}107, \\
0\end{array}$} & \multirow{2}{*}{ Sedang } & \multirow{5}{*}{1} & $\begin{array}{l}\text { Faktor } \quad \text { Kondisi } \\
\text { Fisik }\end{array}$ & 38 & 51 & 47 & 46 \\
\hline & & & & & & & & \multirow{2}{*}{$\begin{array}{l}\text { Faktor Kondisi } \\
\text { Psikologis }\end{array}$} & 10 & 14 & 10 & 13 \\
\hline 4. & 71-90 & & & $\begin{array}{c}87, \\
6\end{array}$ & & Rendah & & & & & & \\
\hline \multirow[b]{2}{*}{5.} & \multirow[b]{2}{*}{$50-70$} & & & & & Sanoat & & Lingkungan & 33 & 55 & 32 & 46 \\
\hline & & & & & & Pandah & & \multirow{2}{*}{$\begin{array}{l}\text { Jumlah } \\
\text { Kondisi }\end{array}$} & 81 & 120 & 89 & 105 \\
\hline & & & & & & & & & 39 & 52 & 44 & 44 \\
\hline
\end{tabular}

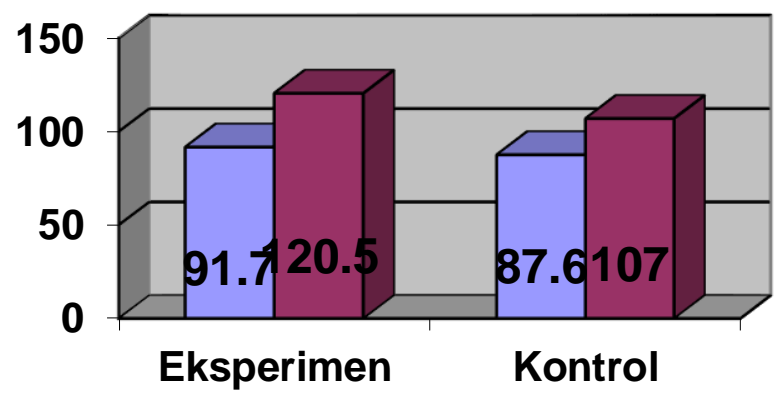

口Pretest

Dari perbandingan tabel per indikator tersebut secara umum telah diperoleh gambaran adanya peningkatan dari masing-masing kelas sampel dari yang sebelum mendapatkan treatment dan setelah mendapatkan treatment. Namun dari perhitungan per indikator ini, masih memilliki sedikit kelemahan dikarenakan dengan perhitungan per indikator hanya diperoleh hasil secara umum saja sehingga tidak diketahui responden yang mana sajakah yang mengalami peningkatan ataupun penurunan dalam mengikuti kegiatan pre-test dan post-test.

Sehingga dengan demikian, untuk mengetahui adanya peningkatan ataupun penurunan dari masing-masing responden dari tiap kelas eksperimen dan kelas kontrol selama mengikuti kegiatan pre-test dan post-test maka akan digambarkan pada perbandingan tabel per sampel. Adapun tabel per sampel tersebut sebagai berikut:

Tabel. 5 


\begin{tabular}{|c|c|c|c|c|c|c|}
\hline & $\begin{array}{l}\text { Faktor Kondisi } \\
\text { Psikologis }\end{array}$ & 12 & 14 & 7 & & mengalami peningkatan dari sebelum mendapat \\
\hline & $\begin{array}{l}\text { Faktor Kondisi } \\
\text { Lingkungan }\end{array}$ & 42 & 55 & 34 & 44 & layanan bimbingan kelompok berjumlah 10 \\
\hline & Jumlah & 93 & 121 & 85 & 102 & prang. Sedangkan yang mengalami penurunan \\
\hline \multirow{4}{*}{3} & $\begin{array}{l}\text { Faktor Kondisi } \\
\text { Fisik }\end{array}$ & 44 & 51 & 45 & 49 & $\begin{array}{l}\text { dar1 sebelum mendapat treatment dan setelah } \\
\text { mendapatkan treatment layanan bimbingan }\end{array}$ \\
\hline & $\begin{array}{l}\text { Faktor Kondisi } \\
\text { Psikologis }\end{array}$ & 12 & 15 & 14 & 14 & kelompok tidak ada. \\
\hline & $\begin{array}{l}\text { Faktor Kondisi } \\
\text { Lingkungan }\end{array}$ & 35 & 55 & 36 & 47 & $\begin{array}{l}\text { Sedangkan hasil pre-test dan post-test } \\
\text { pada kelas kontol dapat dijelaskan bahwa dari }\end{array}$ \\
\hline & Jumlah & 91 & 121 & 95 & 110 & keseluruhan sampel responden dari kelas kontrol \\
\hline \multirow{4}{*}{4} & $\begin{array}{l}\text { Faktor Kondisi } \\
\text { Fisik }\end{array}$ & 39 & 50 & 44 & 43 & yang berjumlah 10 orang yang mengalami \\
\hline & $\begin{array}{l}\text { Faktor Kondisi } \\
\text { Psikologis }\end{array}$ & 10 & 14 & 10 & 12 & $\begin{array}{l}\text { mengalami peningkatan dari sebelum mendap } \\
\text { dreatment dan setelah mendapatkan treatme }\end{array}$ \\
\hline & $\begin{array}{l}\text { Faktor Kondisi } \\
\text { Lingkungan }\end{array}$ & 35 & 55 & 34 & 49 & layanan informasi berjumlah 10 orang. Dan yan \\
\hline & Jumlah & 84 & 119 & $\begin{array}{l}88 \\
\end{array}$ & 104 & mengalami penurunan dari sebelum mendap \\
\hline \multirow{4}{*}{5} & Kondisi & 39 & 53 & 37 & 46 & reatment dan setelah mendapatkan treatme \\
\hline & $\begin{array}{l}\text { Faktor Kondisi } \\
\text { Psikologis }\end{array}$ & 12 & 15 & 10 & 13 & \\
\hline & $\begin{array}{l}\text { Faktor Kondisi } \\
\text { Lingkungan }\end{array}$ & 37 & 55 & 39 & 52 & PEMBAHASAN \\
\hline & Jumlah & 88 & 123 & 86 & 111 & \\
\hline \multirow{4}{*}{6} & $\begin{array}{l}\text { Faktor Kondisi } \\
\text { Fisik }\end{array}$ & 42 & 51 & 43 & 44 & Berdasarkan hasil analisis data di atas, \\
\hline & $\begin{array}{l}\text { Faktor Kondisi } \\
\text { Psikologis }\end{array}$ & 14 & 15 & 12 & 14 & menunjukkan ada perbedaan yang signifika \\
\hline & $\begin{array}{l}\text { Faktor Kondisi } \\
\text { Lingkungan }\end{array}$ & 38 & 55 & 39 & 48 & elompok eksperimen sebelum (pre-test) da \\
\hline & Jumlah & 94 & 121 & 94 & 106 & etelah (post-test) mengikuti kegiatan layanan \\
\hline \multirow{4}{*}{7} & $\begin{array}{l}\text { Faktor Kondisi } \\
\text { Fisik }\end{array}$ & 51 & 52 & 36 & 48 & bimbingan kelompok. Dari uraian diatas, maka \\
\hline & $\begin{array}{l}\text { Faktor Kondisi } \\
\text { Psikologis }\end{array}$ & 14 & 14 & 10 & 13 & $\begin{array}{l}\text { diketahui bahwa ada peningkatan kecerdasa } \\
\text { emosional melalui kegiatan layanan bimbinga }\end{array}$ \\
\hline & $\begin{array}{l}\text { Faktor Kondisi } \\
\text { Lingkungan }\end{array}$ & 41 & 55 & 39 & 48 & relompok. \\
\hline & Jumlah & 106 & 121 & 85 & 109 & \\
\hline \multirow{4}{*}{8} & $\begin{array}{ll}\text { Faktor } \quad \text { Kondisi } \\
\text { Fisik }\end{array}$ & 36 & 49 & 39 & 44 & $\begin{array}{l}\text { Peningkatan hasil pre-test dan post-te } \\
\text { disebabkan karena adanya perlakuan berup }\end{array}$ \\
\hline & $\begin{array}{l}\text { Faktor Kondisi } \\
\text { Psikologis }\end{array}$ & 14 & 14 & 11 & 14 & ayanan bimbingan kelompok yang diberikan \\
\hline & $\begin{array}{l}\text { Faktor Kondisi } \\
\text { Lingkungan }\end{array}$ & 39 & 55 & 35 & 49 & $\begin{array}{l}\text { peneliti. Melalui layanan bimbingan kelompo } \\
\text { iswa mendapatkan berbagai informasi da }\end{array}$ \\
\hline & Jumlah & 89 & 118 & 85 & 107 & \\
\hline \multirow{4}{*}{9} & $\begin{array}{l}\text { Faktor Kondisi } \\
\text { Fisik }\end{array}$ & 38 & 50 & 38 & 42 & kecerdasan emosional. Melalui layanan \\
\hline & $\begin{array}{l}\text { Faktor Kondisi } \\
\text { Psikologis } \\
\end{array}$ & 16 & 15 & 11 & 14 & bimbingan kelompok ini, siswa diberika \\
\hline & $\begin{array}{l}\text { Faktor Kondisi } \\
\text { Lingkungan } \\
\end{array}$ & 36 & 55 & 28 & 48 & dan mengetahui akan pentingnya kecerdasa \\
\hline & Jumlah & 96 & 120 & 77 & 104 & mosional pada diri. \\
\hline
\end{tabular}

Dari hasil pre-test dan post-test pada kelas eksperimen dapat dijelaskan bahwa dari keseluruhan sampel responden dari kelas eksperimen yang berjumlah 10 orang yang
Sedangkan hasil dari pengujian hipotesis diperoleh bahwa peningkatan kecerdasan emosional dapat ditingkatkan dengan menggunakan layanan bimbingan kelompok. Sehingga terbukti bahwa layanan bimbingan 
kelompok efektif untuk meningkatkan kecerdasan emosional siswa. Dari uraian tersebut dapat disimpulkan bahwa layanan bimbingan kelompok merupakan media bagi siswa untuk mengembangkan diri dan memperoleh informasi yang selanjutnya.

Berdasarkan hal tersebut maka peningkatan kecerdasan emosional siswa dapat ditingkatkan dengan menggunakan layanan bimbingan kelompok, hal ini disebabkan karena siswa mendapatkan berbagai informasi, pemahaman dan pengetahuan selanjutnya informasi tersebut digunakan untuk membangun pemikiranpemikiran baru yang mengubah sikap dan perilaku dalam kehidupan pribadinya.

\section{KESIMPULAN}

Kesimpulan umum penelitian ini adalah layanan bimbingan kelompok untuk meningkatkan kecerdasan emosional, namun jika dibandingkan, layanan bimbingan kelompok lebih efektif.

Secara khusus penelitian ini dapat disimpulkan:

a. Dari hasil penelitian yang dilakukan, terjadi peningkatan hasil data pada kelas eksperimen dari sebelum diberikan perlakuan (pretest) dan sesudah diberikan perlakuan (posttest). Begitu juga dengan kelas kontrol terjadi peningkatan hasil data dari sebelum diberikan perlakuan (pretest) dan sesudah diberikan perlakuan (posttest). Tetapi peningkatan hasil data tersebut tidak sebaik hasil data pada kelas eksperimen.

b. Hasil temuan pada kelas eksperimen dan kelas kontrol terdapat peningkatan yang signifikan antara hasil posttest. Rata-rata variabel kecerdasan emosional siswa sebesar 120.50000 pada posttest eksperimen sedangkan pada kelas kontrol sebesar 107.0000, ini terlihat perbedaan yang sangat signifikan. Berdasarkan uraian tersebut juga dapat menjawab hipotesis penelitian yaitu “ Ada peningkatan kecerdasan emosional siswa setelah diberikan layanan bimbingan kelompok dengan pendekatan psikoaalitik pada kelas eksperimen".

\section{DAFTAR PUSTAKA}

Arikunto Suharsimi, 2009. Prosedur Penelitian Suatu Pendekatan Praktik, Jakarta: Rineka Cipta.

Gerald Corey, 2004. Teori dan Praktek dari Konseling dan Psikoterapi (terjemahan). Semarang: IKIP Semarang Pres.

Prayitno, 2004. Seri Layanan Konseling L2 Layanan Informasi, Fakultas FKIPUNP.

Prayitno. 2012. Jenis layanan dan kegiatan pendukung konseling. Padang: FIPUNP.

Sugiyono, 2009. Metode Penelitian Pendidikan, Pendekatan Kuantitatf, Kualitatif dan $R \& D$. Bandung: Alfabeta. 
Volume 3 Nomor 2, Halaman 1-77, Juli-Desember 2018

RISTEKDIK / Jurnal Bimbingan dan Konseling

P-ISSN: 2527-4244, E-ISSN : 2541-206X 